\title{
Regulating Artificial Light at Night: A Comparison Between the South Korean and English Approaches
}

\author{
Martin Morgan-Taylor ${ }^{1, *}$, Jeong Tai Kim²,* \\ ${ }^{1}$ Principal Lecturer, School of Law, De Montfort University, Leicester, LE1 9BH. UK \\ ${ }^{2}$ Professor, Kyung Hee University, Yongin, Korea \\ ${ }^{2}$ President, Korea National Chapter of International Dark-Sky Association
}

Received 09 December 2016, Accepted 28 December 2016

\begin{abstract}
Artificial light at night is associated with safety and security, and the expression well-lit is usually taken to mean brightly lit. Without it human leisure and commercial activities would cease at dusk. However, emerging research indicates that there are problems associated with its use, and these problems are becoming more pronounced with modern lighting practices. It is these problems, which are usually called light pollution, which warrant regulation.

This paper will first outline the reasons why artificial light at night should be regulated; it will then explore the different types of possible regulation, and discuss which forms may offer the best opportunities for good, sustainable lighting. It will finally critically evaluate the "bolt-on” subjective approach of the United Kingdom by way of nuisance and planning regulation, with the merits of the objective metrics system used by the South Korean Light Pollution Prevention Act 2013.
\end{abstract}

Keywords: Light pollution, Regulation, Artificial light at night(ALAN)

\section{Introduction}

Whilst artificial light at night can provide many benefits to society, it may also cause a broad range of problems, and it is submitted that these problems may justify legal regulation. These negative effects can be divided into several broad categories; potential harm to human health and safety, ecological harm, the loss of the night time environment including the night sky, energy waste caused by the inappropriate use of lighting (with wasted greenhouse gas emissions), and general nuisance.

It is submitted that these problems call for careful and balanced regulation. Over-regulation would create an unreasonable burden on business and could also be seen as harmful to safety, security and autonomy. However it must also not fail to address the core problems. It must strike a fair balance between the competing interests of commerce, consumer, and wildlife. Consideration needs to be given to good lighting. So as to ensure that the levels of light used are what is actually needed, when needed, where needed and that an appropriate spectral type of light is used. That is to maximise the benefits whilst minimising the dis-benefits. These usually arise from exterior lighting at night, but there are circumstances where they may be caused by interior lighting. These problems must be fully understood in order to assess whether regulation is deemed appropriate.

This paper will first outline the reasons why artificial light at night should be regulated; it will then explore the different types of possible regulation, and finally critically evaluate the "bolt-on" subjective approach of the United

* Corresponding Authors: Martin Morgan-Taylor, E-mail address: mart@dmu.ac.uk Jeong Tai Kim, E-mail address: jtkim@khu.ac.kr 
Kingdom to nuisance and planning regulation with the merits of the objective metrics system used by the South Korean Light Pollution Prevention Act 2013.

The first issue to address is why artificial light at night, with its clear advantages to business, safety and security as well as public amenity should be subject to any regulation at all.

\section{Human Health}

Artificial light at night may harm human health. It may disturb sleep by shining into bedroom windows, and it is well settled under English law that the courts accept that sleeplessness can harm health [1] ${ }^{1}$. However emerging medical research indicates more serious negative effects. ${ }^{2}$ Indoor lighting may increase the risk of certain forms of cancer in humans (e.g. breast and colo-rectal), because light at night can alter the brain's biochemistry by the inhibiting production of Melatonin, (an antioxidant that protects the body from certain cancers) [2-5] $]^{3}$. Melatonin is produced at night, but only if it is dark. This research has led the World Health Organisation (WHO) along with the American Medical Association (AMA) and European Commission [6-11] $]^{4}$, to issue a call for more research.

Studies show that it is daylight type (blue rich) lighting which suppresses Melatonin the most [12-13 $]^{5}$. Marketed due to energy efficiency, the most efficient types of LED emit the most heavily in the blue. A missing part of the equation is the exact level and duration of exposure required to constitute an unacceptable risk to human health. Or whether exterior lighting represents any risk at all. However many local authorities are installing blue rich LED street lighting, due to the financial savings that these LEDs are said to offer. These may shine into bedroom windows. Even so, it is submitted that sleep disturbance, which is quite well settled legally, justifies regulation in its own right.

\section{Ecological Health, Safety, Energy Waste and the Loss of the Night Sky}

There are similar problems posed to ecological health, and these along with the loss of the night sky have been addressed elsewhere [14-15] $]^{6}$. To summarise, there may be similar effects to caused ecological health; the view of the night time sky is being blocked out by artificial light, and wasted light is wasted energy, carbon emissions and money. However the problems caused by glare, and nuisances in the form of the loss of sleep, or the general loss of quality of life will be discussed here.

\footnotetext{
${ }^{1}$ Lewisham v Fenner, [1995] 248 ENDS Report 44. However, on appeal the court held that although sleeplessness can amount to an injury, this was not made out in the instant case as the levels of noise complained of were well below those recommended for intrusive noise. 2 For a data base of abstracts see in particular: http://www.trianglealumni.org/mcrol/References-With_Abstracts.pdf [home page on the Internet].

3 For example, Eismann, E.A, Lush E, and Sephton S. E, Circadian Effects in Cancer-Relevant Psychoneuroendocrine and Immune Pathways, 35 Psychoneuroendocrinology, 7,963-976 (2010); Stevens R.G, Light-at-Night, Circadian Disruption and Breast Cancer: Assessment of Existing Evidence, (2009) 38 International Journal of Epidemology 963; Pauley S.M, Lighting for the Human Circadian Clock: Recent Research Indicates That Lighting has Become a Public Health Issue, 63 Medical Hypotheses 588-596 (2004); Kloog I et al, Global Co-Distribution of Light at Night (LAN) and Cancers of Prostate, Colon, and Lung in Men, 26(1) Chronobiol. Int., 108-125 (2009). 4 The World Health Organisation International Agency for Research on Cancer (IARC), IARC Monographs Programme finds cancer hazards associated with shiftwork, painting and firefighting, International Agency for Research on Cancer, Press Release 180, 5th December 2007; the European Commission, Directorate-General for Health \& Consumers Scientific Committee on Emerging and Newly Identified Health Risks (SCENIHR) has also called for more research in this field, Health Effects of Artificial Light (2011). Available at: http://ec.europa.eu/health/scientific_committees/emerging/docs/scenihr_o_033.pdf accessed 1 April 2016.

International Agency for Research on Cancer, 2007; European Commission (SCENIHR, 2011); and AMA Report 4 of the Council on Science and Public Health (A-12) 6/21/2012

Light Pollution: Adverse Health Effects of Night time Lighting, authors: Blask D, (Tulane University School of Medicine); Brainard G, Gibbons R, Lockley S, Stevens R and Motta M.

${ }^{5}$ Lockley S.W, Brainard G, Czeisler C, High Sensitivity of the Human Circadian Melatonin Rhythm to Resetting by Short Wavelength Light, 88(9) J Clinical Endocrinology. METAB., 4502-5 (2003); Kayumov L et al, Blocking Low-Wavelength Light Prevents Nocturnal Melatonin Suppression with no Adverse Effect on Performance During Simulated Shift Work, 90(5) J. Clin. Endocrinol. Metab., 2755-2761 (2005).

${ }^{6}$ Rich C and Longcore T (eds), Ecological Consequences of Artificial Night Lighting, (Island Press, 2006); Royal Commission on Environmental Pollution, Artificial Light in the Environment, UK (2009).
} 


\section{Glare}

Artificial lighting may harm safety either directly via disability glare or by distraction. Disability glare may occur for example, where a badly angled security light shines into the eyes of motorists masking objects or people. This may result in accidents caused by the lighting. Such glare may also result from security lighting angled outwards and into the eyes of potential onlookers, rather than downwards illuminating the criminal. Such security lighting is said to be beneficial because it allows opportunities for passive surveillance, in that it may permit passers-by to see criminal activity and report it. However the glare caused by angling the light outwards destroys the opportunity for passive surveillance, by shining the light into the eyes of the passers-by masking the criminal from sight. The result is that lighting that is put up for safety and security can actually have the opposite effect, and can also result in other problems to sleep and quality of life generally.

Clearly these forms of lighting, which have often been put up to serve safety and security may harm both interests. As such regulation may serve a positive role in ensuring that lighting is fitted correctly so as to serve its' intended purpose. Distraction may occur, for example, where a motorists' attention is diverted away from the road by illuminated advertising. The balance here is claim for a commercial need for illuminated advertising, set against the claim for accident risks.

\section{Nuisance (Light “Trespass”)}

Artificial light at night can also cause broad problems that relate to an interference with the quality of life that are not directly related to health. These problems may come from unwanted spill light shining into a bedroom window disturbing sleep, glare from light shining into eyes, or general complaints about an unpleasant atmosphere caused by lighting.

These problems are often referred to as "light trespass". However trespass has a legal meaning and the effects caused by artificial light have not been held to constitute trespass in many jurisdictions law, (including England and the USA). As such the use of this expression might be a source of confusion for regulators.

There is however case law concerning light nuisance in some common law jurisdictions, such as the UK and USA [16] $]^{7}$. However lighting must meet certain criteria to constitute a nuisance in law. The challenges for lighting in meeting these criteria will be addressed later in the section reviewing the "bolt on" approach to regulation in England. In addition to common law nuisance, where an individual can take the owner of a light to court to get the light nuisance abated (reduced or stopped), England has recently added artificial lighting to the list of possible "statutory" nuisances in recognition of some of these problems [17] ${ }^{8}$. (These concepts will also be addressed later.)

A study carried out for the UK Defra (Department of Environment, Food and Rural Affairs) [18 $]^{9}$ reviewed the sources of general nuisance complaints from lighting to local authorities. Domestic security lighting was by far the largest in the "domestic" sub-category (1760 of 2475 complaints) [18 $]^{10}$. These lights are commonly fitted angled outwards, creating the glare that may be dangerous to road users, or spill light into windows or the sky as set out above.

The study also sub-categorised other locations of nuisance lighting complaints to local authorities. Of the 180 documented nuisance complaints from "sports" facilities, 68 were from football or hockey pitches, 33 from tennis courts, 33 from golf driving ranges, with 11 from rugby pitches. Of the 384 complaints from the "industrial" subcategory, the vast majority (209) were from factory security lighting, the second highest (34) were from car parks. Of the 796 complaints from "commercial” lighting, shop security lighting was top (131), shop advertising second (95), then office security lighting (66) and car parks (60) [18] ${ }^{11}$.

\footnotetext{
7 Morgan-Taylor, M, Light Pollution, Nuisance and Planning Laws in the UK: The Legal Methods of Controlling Light Pollution in the UK. Published proceedings of the 8th Sustainable Healthy Buildings Conference, Seoul, 2012. See: http://www.sustainablehealthybuildings.org/PDF/8th/martintaylor.pdf

${ }^{8}$ Morgan-Taylor, M, Regulating Light Pollution in Europe: Legal Challenges and ways Forward, in Urban Lighting, Light Pollution and Society, Meier, J, Hasenohrl, U, Krause, K (eds), Routledge (2014).

${ }^{9}$ NANR 284, An Investigation into Artificial Light Nuisance Complaints and Associated Guidance, Defra, (2010), London, England.

${ }^{10}$ Ibid, pp24-29.

${ }^{11}$ Ibid. NANR 284, pp 23-29.
} 
There is a similar nuisance problem in Korea, with the following numbers of complaints to the Seoul City authorities (population ten million) [19] ${ }^{12}$ :

Table 1. Numbers of complaints to the Seoul City authorities (population ten million).

\begin{tabular}{cccccc}
\hline Year & Sleep & Life & General glare & Other & Total \\
\hline 2015 & 1043 & 73 & 59 & 2 & 1177 \\
\hline 2014 & 1424 & 136 & - & 11 & 1571 \\
\hline 2013 & 547 & 186 & - & 40 & 773 \\
\hline
\end{tabular}

These problems highlight the need for an effective control of the broad types of nuisances that are commonly the subject to complaint.

\section{Legal Regulation of Light at Night}

Now that the broad problems justifying the regulation of artificial light at night have been set out, we may now consider the possible mechanisms for legal control ${ }^{13}$. These mechanisms must be able to address these key problems, whilst at the same time protecting the benefits that artificial light at night may offer. So regulation must be a balanced response to the problems that does not harm commercial interests or social utility where possible. There are several possible forms that this regulation may take. It may firstly come from hard binding law. For example it may come from sector specific laws such as planning regulation, building regulations, nuisance, public health or environmental laws. It may come in the form of dedicated legislation aiming to address all or some of the problems set out above. Or it may come from bolting it on to pre-existing legislation such as planning or nuisance laws. Regulation may also come from soft law, in the form of non-binding guidance, written by government, the lighting industry, and/ or environmental stakeholders such as the International Commission on Illumination (CIE) [20] ${ }^{14}$, or from ecological certification organisations such as the UK's Buildings Research establishment (BRE) [21] $]^{15}$. Guidance can help educate, so as to increase the levels of understanding of the underlying purpose of the regulation. Such understanding should increase compliance and reduce the need for conflict (and cost), in the form of enforcement.

Regulation may include subjective nuisance based concepts that are to be interpreted by local authorities. Or it may include a metrics based system with limits, curfews, or a mixture of these. Metrics may be used to provide either guidance or hard limits as to the levels of light, (or the types of light) that may be permitted. Metrics may also come from a variety of sources, including the lighting industry, national governments or international standards organisations such as the CIE. They may be based on experimental data or the judgment of experts in study groups. Or they may be based on what is achievable commercially given the impact of regulation on manufacturers and retailers.

Bolting onto existing legislation, offers a quick and cheap way to regulate, by avoiding the time and expense of generating new legislation. However this is at the expense of coverage; it will only cover those aspects of light at night within the scope of the pre-existing laws involved. (England's planning and statutory nuisance regimes are good examples of this approach.) Dedicated provisions, formulated specifically to address the negative effects of artificial light at night may be more effective. Unlike bolt on provisions, they have the potential to address all of the environmental and human health problems. The Korean dedicated provisions that will be discussed below, serve as a good example for balancing the competing interests between the advantages and disadvantages of lighting. Such legislation comes from a very good understanding of the problem, and it may be less vulnerable to calls for repeal.

Regulation may benefit from the input and support of stakeholder groups, such as the lighting industry and environmental groups. However, it is accepted that agreement here may be limited because it may be difficult to reconcile the different objectives of each group. Although this gives some control and ownership to these stake

\footnotetext{
12 Kim JT (2016), Legislative Approach of Preventing Light Pollution in South Korea, LUCI AGM 2016 Conference, Seoul, South Korea, Data supplied by the Korean Ministry of Environment, August 2016.

${ }^{13}$ Morgan-Taylor M, "Regulating Light Pollution in Europe: Legal Challenges and Ways Forward”, in Josiane Meier et al (eds), Urban Lighting, Light Pollution and Society, (Routledge 2015).

${ }^{14}$ CIE 150, Guide on the Limitation of the Effects of Obtrusive Light from Outdoor Lighting Installations, (Vienna, 2003).

15 Buildings Research Establishment Environmental Assessment Method (BREEAM), England. See: http://www.bre.co.uk/
} 
holder groups. Soft law input in the form of guidance may assist hard law, in providing clear detail as to what is and is not acceptable, and it may offer alternatives. Any agreement between the lighting industry, business groups and environmentalists would be constructive and such agreement would also reduce possible challenges to the regulation.

All of these types of regulation may be applied on a local or regional level via a local authority, a whole nation, or to a number of nations in a trade bloc, such as the European Union.

There is national legislation in a growing number of countries. For example, individual states in the USA [22 $]^{16}$, The Republic of Korea [24] ${ }^{17}$, France ${ }^{18}$, Slovenia ${ }^{19}$, England [25] ${ }^{20}$ and many Italian regions ${ }^{21}$. England and Korea will be used as exemplars because they cover significantly different approaches. England has a bolt on system that does not use binding metrics, whilst the Korean system is a bespoke law that uses metrics. Both countries also cover a wide geographical area as well as different legal traditions.

\section{England (Bolt On)}

Unlike Korea, regulation in England uses the bolt on approach, incorporating light at night into existing hard law concerning planning and nuisance, rather than by the use of dedicated legislation. This is supplemented by a number of guidance notes from central government and the lighting industry, working with stakeholders such as environmental bodies.

Light pollution is a factor for consideration at the planning stage for new buildings in England [26] ${ }^{22}$. However, this bolt on approach has weaknesses. For example, English planning law limits consideration on existing buildings to cases where there is "development", that is an impact on the daytime visual appearance of premises ${ }^{23}$. This is because the planning system is more interested in the appearance of the light fittings, rather than the problems actually caused by the light fittings. Yet night-time floodlighting is a key cause of problems with artificial light at night. LED lighting generally emits light from smaller, more compact light sources than traditional lighting. So, floor mounted upwardly pointing LED floodlighting may be less likely to be viewed as a 'development' attracting planning control, because it is less prominent during daytime hours. However, the effects of the light may be just as great.

Until the British Government recently published a guidance note on light pollution and planning [27] ${ }^{24}$, there had been no clear practical guidance on what exactly developers were or were not allowed to do. This led to regulatory conflict with a lack of transparency for lighting designers, users and consumers, and an inconsistent response from local authorities. Indeed it has been an occasional practice in England for planning committees to accept without question assurances that "we are using modern LED lighting, so there will be no light pollution".

\footnotetext{
${ }^{16}$ For example, California (CEC-400-2008-001-CMF, California Energy Commission (CEC) Title 24: Energy Efficiency Standards for Residential and Nonresidential Buildings, December 2008); Delaware (applicable to state lighting, Title 7: Conservation \& Natural Resources, Chapter 71A. Regulation of Outdoor Lighting.

${ }^{17}$ Light Pollution Prevention Act 2013, Ministry of Environment, Seoul, Republic of Korea 2013.

${ }^{18}$ Arrêté du 25 janvier 2013 relatif à l’éclairage nocturne des bâtiments non résidentiels afin de limiter les nuisances lumineuses et les consommations d"énergie. (Decree of 25 January 2013 on the "night light non-residential buildings in order to reduce light pollution and consumption of energy".)

${ }^{19}$ See Government Regulation 4162 on the Limits of Light Pollution of the Environment, on the basis of Article 17, paragraph 3 and 5 of the Environmental Protection Act. Official Gazette of the Republic of Slovenia, No. 39/06 -official consolidated text, 49/06 - Law on Meteorological Activities, 66/06 - Decision of the Constitutional Court and 33/07 - Spatial Planning Act, adopted by the Government of the Republic Slovenia, Regulation About the Limits of Light Pollution on the Environment.

${ }^{20}$ Statutory nuisance, s. 79(1) Environmental Protection Act 1990.

${ }^{21}$ See for example, Lombardy (Law of the Lombardy Region no. 17 of 03/27/2000, Urgent measures to fight the light pollution and to achieve energy saving in the use of outdoor lighting); Veneto, Law No. 17 of August 7, 2009, No Bur 65 of 11/08/2009, New standards for light pollution, energy saving outdoor lighting and for the protection of the environment and the activities carried out by astronomical observatories.

${ }^{22}$ National Planning Policy Framework, para. 175, Department for Communities and Local Government, March 2012: https://www.gov.uk/government/uploads/system/uploads/attachment_data/file/6077/2116950.pdf.

${ }^{23}$ Kensington and Chelsea Borough Council v. CG Hotels and Another (1981) JPL 190, and see generally Grant, supra note 129, at 159 et seq.

${ }^{24}$ Light Pollution, When is Pollution Relevant to Planning?, Defra (UK), 2013, available at:

http://planningguidance.planningportal.gov.uk/blog/guidance/light-pollution/when-is-light-pollution-relevant-to-planning/ accessed 1 April 2016.
} 
Supplementary (soft law) guidance from the lighting industry and other environmental interest groups can also have a significant role to play in bolt on regulation. The United Kingdom's Institute of Lighting Professionals (ILP) provides Guidance Notes for the Reduction of Obtrusive Light $[28]^{25}$, which offer clear guidance on avoiding over-lighting, and provides diagrams on how to fit light fittings correctly. The guidance is drafted with input from several environmental stakeholders, and is well respected in the United Kingdom.

English statutory nuisance serves as another example of bolt on legislation. However, the most fundamental problem with bolting light pollution onto existing nuisance legislation is that artificial light at night causes problems far wider than the narrowly defined criteria that trigger the nuisance regime; that is the effects on everyday enjoyment of property interests, rather than broader environmental and ecological concerns noted earlier ${ }^{26}$. Many of the complaints addressed above may come into a much wider category of "nuisance" that falls outside of the legal definition.

Artificial light at night was recently added to the list of potential statutory nuisances under the Environmental Protection Act 1990. So that it covers "artificial light emitted from premises so as to be prejudicial to health or a nuisance" ${ }^{27}$. Local authority environmental health services are obliged to investigate complaints made by members of the public. However, this has the same problem of scope of coverage. S.80 EPA empowers the local authority to assess whether the artificial lighting breaches either or both of the two statutory nuisance limbs. That is, whether it is prejudicial to health, a nuisance, or both. The standard required by the health limb is an objective one and set at a higher standard than the second nuisance limb. In Birmingham CC v Oakley ${ }^{28}$ prejudice to health covers " ... what may be actually injurious as well as what may be likely to be injurious and (is) in either case something over and above what may be seen as a "nuisance".

It requires credible scientific evidence that, on balance of probabilities, artificial lighting is harmful to health, or that exposure to it represents a significant risk. Whilst it is expected that sleep disturbance is recognised as a possible consequence, the other negative effects on human health (such as cancer), probably presently fall short of this evidential hurdle.

The second (nuisance) limb offers more of an opportunity for coverage of light at night. This element deals with the interference of personal comfort that is not directly linked with human health [29-31 ${ }^{29}$. This second (nuisance) limb includes public as well as private forms of nuisance. The requirement for private nuisance requires that the lighting must be emitted from premises and have an affect on other premises. The lighting must also unreasonably interfere, in a material or substantial way, with the victim's use of their property. The nuisance limb also requires interference to a person's "personal comfort" [29] ${ }^{30}$. This is assessed objectively, and it will not apply to what a hypersensitive victim regards as interference in their personal comfort if a person of average sensitivities would not regard it as such. There is existing case law where the broadly equivalent criteria for private nuisance have been accepted by the courts under statutory nuisance, where car park [32] ${ }^{31}$ or sports facility lighting [33] $]^{32}$ has shone into windows, or disturbed night fishing $[34]^{33}$. However the energy waste or harm to ecological health that can be caused by artificial light at night are not tied to enjoyment of premises and so will not be covered. The issue with the loss of the view of the night sky is whether the loss of a hobby amounts to an unreasonable interference of property rights. Perhaps it might, given that the pursuit of hobbies is important for mental wellbeing, and offers business a market for hobby products. However it is likely that such interference will not be held to cross the threshold.

As a result the nuisance regime is not the right avenue to use to adequately regulate artificial light at night. It presents a reactive mechanism and so is unable to prevent lighting problems arising in the first place, (planning

\footnotetext{
${ }^{25}$ GN01:2011. Available at: http://www.theilp.org.uk/documents/light-pollution/

${ }^{26}$ For a full examination of the limitations of the coverage that nuisance may give to light pollution see, Morgan-Taylor M, Light Pollution, Nuisance and Planning Laws in the UK: The Legal Methods of Controlling Light Pollution in the UK. Published proceedings of the 8th Sustainable Healthy Buildings Conference, Seoul, 2012. See: http://www.sustainablehealthybuildings.org/PDF/8th/martintaylor.pdf 
would be the opportunity to address these problems). It is also limited in scope. The health test covers only known health problems backed up by a credible body of existing medical evidence, not emerging unsubstantiated claims of possible links to cancer that require further investigation and evidence. It is also limited in that it only protects against interference in everyday property enjoyment, and again it is not designed to protect against the wider environmental, such as the loss of the night sky or even the energy waste issues.

The nuisance regime is based on a considerable degree of subjective judgment on the part of the local authority and judge. Whilst the metrics of the CIE or ILP may be cited in court they will only be persuasive to a judge and not binding. (For example set maxima permitted to enter bedroom windows at night.) The bolt-on nuisance approach offers a mixture of advantages and disadvantages. It certainly provides the flexibility to give a just result to a complaint, but at the expense of certainty and transparency. For example, commercial applicants may not know what they can/cannot do. Consumer complainants may fail to bring an action if the outcome is uncertain without metrics, fearing the costs should they lose. Regulators are also faced with financial policy considerations, and will be expected to focus their resources on "core" policy areas. These rather new and untested concepts of nuisance from artificial light are unlikely to be acted on by a local authority unless the negative effects are so serious that they deem it very safe to take a case to court.

Even though metrics serve as soft guidance only, the UK Institution of Lighting Professionals has produced a guidance note on the reduction of light pollution [35] $]^{34}$. This includes a table of metrics that may be used for objective guidance in assessing nuisance and lighting levels at planning stage. The table suggests maximum levels for the escape of light that may be deemed acceptable. These figures are a modified form of those given by the international lighting body, the International Commission on Illumination $[20]^{35}$. The guidance breaks areas down into a series of zones, from 0 to 4 , with different maximum levels of stray light recommended. (E0 is for a dark sky park, and E4 for a large inner city area.) It also suggests the use of curfews, where lighting that is not needed is switched off.

\section{Republic of Korea (Metrics)}

The Republic of Korea (South Korea) has adopted a dedicated law [36] ${ }^{36}$ using a variation on the metrics suggested by the CIE $[20]^{37}$, which it makes binding. Metrics can provide objective set limits to the amounts of light that are permitted. This objectivity gives metrics several advantages. Firstly, they are free from the uncertainty of that exists under the (subjective) English nuisance law. A level is either permitted or it isn't, so the rules are very clear and transparent. As such lighting designers, and users of lighting (commercial, public sector or consumer users) as well as enforcement authorities will have a much clearer indication as to what is and is not permitted. Lighting users can confidently use lighting within these limits. This avoids the need to commit financial resources on failed legal action. Similarly, enforcement bodies are on much stronger ground when approaching the owners of offending lighting. The clarity offer by metrics will avoid authorities having to prioritise and risk financial resources in taking cases to court, so leading to more compliance and less court cases. Consumers suffering from light shining into bedroom windows for example, will also be on a stronger ground to complain if the lighting exceeds that given in the metrics. However in order to achieve this, the metrics used must be freely available to all (including consumers), otherwise the system would fail to offer all parties equal transparency and access.

A disadvantage of a metrics system comes from its' great strength in certainty. That is, the certainty lacks flexibility, because a fixed maximum might not reflect the full circumstances because there might be other factors coming into play. For example, there may subjectively be a problem from the combined effect of say light with noise, where the individual levels of both light and noise are in themselves below the maximum metric. However the perception of their combined effect might cross the threshold. Similarly, the irritation caused by flashing lighting might be deemed worthy of a lower set maximum. However metrics could offer a solution by devising a rule to compare several metrics, such as the combined effect of say light and noise.

Metrics may also fail to address the different effects of human perception caused by the colour of the lighting. Blue rich light for example might provide a greater disturbance than a soft yellow, because it may appear brighter

\footnotetext{
${ }^{34}$ Guidance Note on the Reduction of Light Pollution, GN01:2011. Available at: http://www.theilp.org.uk/documents/light-pollution/

35 CIE 150, Guide on the Limitation of the Effects of Obtrusive Light from Outdoor Lighting Installations, Vienna, 2003.

${ }^{36}$ Light Pollution Prevention Act in Korea 2013. Ministry of Environment, Seoul, Korea, 2013.

37 CIE 150, Guide on the Limitation of the Effects of Obtrusive Light from Outdoor Lighting Installations, Vienna, 2003.
} 
to the human eye. This is where the bolt on nuisance regime of England has an advantage, in as much as the enforcer may evaluate the total effect of the lighting, using wider concepts than a fixed set of metrics. As a result, the question is whether the benefit of certainty is outweighed by the dis-benefit of a lack of flexibility. It is probably true to say that any metrics system takes an "organic" form, evolving as human understanding progresses to take on board new understandings of lighting practices, and the negative effects that they might have. As such metrics which are reviewed and updated offer a very good opportunity for regulation.

The CIE 150 and Korean systems zone areas into four environmental zones (E zones) ranging from E1 (the darkest), to $\mathrm{E} 4$ (the brightest). E1 is reserved for countryside areas, whilst $\mathrm{E} 4$ is for commercial city areas requiring the highest levels of lighting. (The E0 zone is a UK addition to the CIE metrics.) The zones are determined by the use of land under the Korean Law on National Land Planning and Use. The advantage of such a zoning scheme is again transparency to all of the parties affected light at night, business, consumer as well as the regulator.

The Korean law provides a variation on the CIE 150 figures for these zones. The table shows compares the CIE 150 and the Korean figures, with the Korean statistics given in parenthesis and bold. The Korean maxima apply from 60 minutes after sunset until 60 minutes before sunrise.

Table 2. A comparison of CIE150 to Korean lighting ordinance values

\begin{tabular}{cccc}
\hline Item & $\begin{array}{c}\text { Vertical illuminance on windows. } \\
\text { (Light coming into windows.) } \\
\text { (Lumens/m2) }\end{array}$ & $\begin{array}{c}\text { Maximum luminance from } \\
\text { illuminated building facades } \\
\text { (Candellas/m2) }\end{array}$ & $\begin{array}{c}\text { Maxima for average surface } \\
\text { luminance of illuminated signs } \\
\text { (Candellas/m2) }\end{array}$ \\
\hline E1 & $2(10)$ & $0(20$ with an average of 5) & $50(50)$ \\
\hline E2 & $5(10)$ & $5(60$ with an average of 5) & $400(400)$ \\
\hline E3 & $10(10)$ & $10(180$ with an average of 15) & $800(800)$ \\
\hline E4 & $25(25)$ & $25(300$ with an average of 25) & $1,000(1,000)$ \\
\hline * Both CIE and Korean statistics are given, with the latter in parenthesis and bold. & \\
The Korean maxima apply from 60 minutes after sunset until 60 minutes before sunrise. &
\end{tabular}

The Korean values are identical to the CIE for illuminated advertising but higher than those under CIE150 for window illuminance (light coming into windows) in the more stringent zones E1 and 2. The higher levels may be due to the population density of Korea leading to more extraneous light. It may also represent an opportunity to give commerce time to adjust to regulation with a fairly easy to meet high maximum, before reducing it at a later date to be in line with CIE 150 values. The Korean levels for the illumination of structures are also higher, but although their maxima are considerably higher, they involve an average that is almost in line with the CIE figures. As such Korean building illumination may be compliant if the structure contains both brightly lit and unlit (or dimly lit) sections. However the issues caused by light at night, for example light intrusion, might be more a result of the maximum levels of light rather than their average levels. These maxima might permit what might otherwise be considered over-illumination of buildings.

A disadvantage of a zoning policy like this is that like noise, light travels across different lighting zones. This is particularly a problem in densely populated countries, such as many in Europe and South Korea. Similarly, city areas may contain mixed-use areas containing both commercial and residential buildings, and these areas often have illuminated billboards opposite apartment blocks. However, it is possible that the law could in time also adopt curfews so that illuminated billboards etc must be switched off completely at a given time. This would mean that the need to sleep is deemed to outweigh the economic merits for illuminated advertising in the early hours of the morning, (11pm or midnight to 6am perhaps).

It is also important to discuss what these maximum figures actually mean in practice, and the importance in educating all of the parties involved, including the enforcement bodies. The Korean metrics prescribes that there should be no more than 25Lux of light entering a bedroom window in an inner city area in the heart of the commercial district. It might be easy for regulators to assume that a light level of 30Lux is only a little over the 25 limit and so permit it. By comparison, the maximum light of the Full Moon is less than 0.5Lux. So 5Lux equates to at least 10 Full Moons, and an average lounge is lit to about 10Lux in the evening. There have been cases in England where planning authorities have been referred to the (non-binding) metrics in England and made this mistake, passing planning applications where the light levels exceed the metric by 3-5Lux. This clearly raises issues of education, where regulators might take a different decision if they realised what the statistics actually meant in practice.

Both the maxima under these objective metrics and the subjective English nuisance laws show the difficulties in balancing the competing interests between the commercial use of lighting and the right to a dark bedroom. To 
what extent might it be suggested that the victim be responsible for the light levels, and fit blackout curtains at their own cost? It is suggested that it would be wrong to place the cost and burden of abatement on the victim. Complainants should never be told to fit thicker curtains where the real source of the problem is the lighting; if the problem results from the failure to employ best practicable means so as to avoid the nuisance. However location might be an important factor, as what is seen as reasonable behaviour will vary from the countryside to an inner city area. It is probably unreasonable for a city centre dweller to fit no curtains at all, where even with the use of best practicable means the light levels would disturb the reasonable person without curtains. However, it should always be unreasonable to expect a complainant to pay for blackout curtains that must be fitted tightly in order to prevent bright light from entering a bedroom window. It has been suggested at an English planning application for cricket ground lighting in a residential area, that the cricket club might offer to pay for blackout curtains, (although no condition was imposed on the applicant). Further this does not take on board the wider use of property that may be affected by lighting. It may put residents off using their gardens; late evening BBQs in summer for instance.

Effective regulation needs effective enforcement powers. The Korean law provides this opportunity. Local authorities have enforcement powers to fine and/or impose a compliance order, which offenders must comply with within three months. (This is similar to the British statutory nuisance regime as it takes the cost and burden away from the victim.) The fine rises with the severity of the breach of the lighting levels, and increases from a first offence through a second, to a third offence, committed within 12 months. The escalation of fines is a good way to ensure compliance. The lowest fine is 50 USD is for a first violation of less than 1.5 times the lighting standard. It increases to 1,000 USD for a third violation. Whilst the highest fine is reserved for violators who fail to obey a compliance order. Here the fine is 2,500 USD for the first violation, rising to 10,000 USD for a third. Violators who block or hinder the assessment of the lighting by the local authority are subject to a fine of 250 USD for a first violation, rising to 1,000 USD for a third offence. Such fines should help to put violators off blocking an investigation, hoping that the local authority will give up, or be called to more serious offence elsewhere. However, it remains to be seen whether local authorities will be able to, or willing to put in the resources to investigate offences with fines of 50 USD.

Fines may be reduced by up to $50 \%$ if the violation is deemed an error (which risks compliance of the enforcers), but does offer a partial defence for genuine mistakes. It may also be reduced by $50 \%$ where the violators are making reasonable attempts to reduce the offence. However, no fine can be reduced which the violator has previously failed to pay.

So the objective metrics system with a comprehensive enforcement mechanism, at least on paper, has much to commend it. However the limits of strict maxima that lack flexibility tend to dilute the likely effectiveness of this approach.

\section{Conclusion}

This paper has attempted to demonstrate that artificial light at night may cause a wide range of interdisciplinary problems for human health, ecology and the natural environment that are sufficiently serious to warrant legal regulation. We have set out the different mechanisms by which this regulation may take place, and compared the subjective bolt-on approach taken in England, with the dedicated (metrics based) law in Korea.

The English regime offers flexibility, in that all criteria may be weighed up, in a way that is most suitable for deciding the case. It may also be well suited to evolve as human understanding of the problems that may be caused by artificial light at night evolves. However, this bolt on approach is severely limited to cover only the pre-existing criteria for concepts such as nuisance in law. Whilst the problems that light at night can cause are far broader. Further, the English nuisance approach can only be effective if the regulators fully understand the problems that lighting may cause, and how they may be abated without compromising the positive benefits that light at night may have. This subjective approach also lacks clarity and certainty. As a result it is often not clear to commerce exactly what lighting is permitted and what is not. Further, regulators may be far less likely to risk financial resources and time in pursuing lighting cases because of this lack of certainty, instead prioritising more graphic breaches of other regulations. The net result is that a subjective opinion on a poorly a poorly understood problem is unlikely to result in action.

The Korean approach uses a dedicated law, and so it is written from the outset to address the broad problems that artificial light at night may cause. It gets round the lack of clarity and lack of certainty of the English system 
by using binding metrics. Such an objective system offer transparency for business, consumer and regulator. It makes the enforcement system simpler and is far more likely to result in enforcement than the English system. However it lacks the flexibility of the English system. On balance however, it is submitted that a Korean metrics based system has the edge over the English system. If the metrics system is reviewed and updated to reflect current knowledge, and that the light limits represent a fair balance of the competing commercial/consumer interests. Similarly, a metrics system must have a mechanism for taking into account a mixed problem, of say noise and light, which might not breach the lighting metric. A well understood metrics system that is regularly enforced is ultimately better than a more flexible system that is poorly understood and even more poorly enforced.

\section{References}

[1] Fenner, L.V. (1995). 248 ENDS Report 44.

[2] Eismann, E. A., Lush, E., \& Sephton, S. E. (2010). Circadian effects in cancer-relevant psychoneuroendocrine and immune pathways. Psychoneuroendocrinology, 35(7), 963-976.

[3] Stevens, R. G. (2009). Light-at-night, circadian disruption and breast cancer: assessment of existing evidence. International journal of epidemiology, 38(4), 963-970.

[4] Pauley, S. M. (2004). Lighting for the human circadian clock: recent research indicates that lighting has become a public health issue. Medical hypotheses, 63(4), 588-596.

[5] Kloog, I., Haim, A., Stevens, R. G., \& Portnov, B. A. (2009). Global Co-Distribution of Light at Night (LAN) and Cancers of Prostate, Colon, and Lung in Men. Chronobiology international, 26(1), 108-125.

[6] International Agency for Research on Cancer. (2007). IARC Monographs Programme finds cancer hazards associated with shiftwork, painting and firefighting. World Health Organization, Lyon.

[7] Directorate-General for Health \& Consumers. (2011). Scientific Committee on Emerging and Newly Identified Health Risks (SCENIHR). Health Effects of Artificial Light. Available at: http://ec.europa.eu/health/scientific_committees/emerging/docs/scenihr_o_033.pdf.

[8] International Agency for Research on Cancer. (2007).

[9] European Commission. (2011). Scientific Committee on Emerging and Newly Identified Health Risks (SCENIHR).

[10] AMA Report 4 of the Council on Science and Public Health (A-12). (2012).

[11] Blask, D., Brainard, G., Gibbons, R., Lockley, S., Stevens, R., Motta, M. Light Pollution: Adverse Health Effects of Night time Lighting. Tulane University School of Medicine.

[12] Lockley, S. W., Brainard, G. C., \& Czeisler, C. A. (2003). High sensitivity of the human circadian melatonin rhythm to resetting by short wavelength light. The Journal of clinical endocrinology \& metabolism, 88(9), 4502-4502.

[13] Kayumov, L., Casper, R. F., Hawa, R. J., Perelman, B., Chung, S. A., Sokalsky, S., \& Shapiro, C. M. (2005). Blocking low-wavelength light prevents nocturnal melatonin suppression with no adverse effect on performance during simulated shift work. The Journal of Clinical Endocrinology \& Metabolism, 90(5), 27552761.

[14] Rich, C., Longcore, T. (2006). Ecological Consequences of Artificial Night Lighting. Island Press.

[15] Royal Commission on Environmental Pollution. (2009). Artificial Light in the Environment. UK.

[16] Morgan-Taylor, M., (2012). Light Pollution, Nuisance and Planning Laws in the UK: The Legal Methods of Controlling Light Pollution in the UK. Published proceedings of the 8th Sustainable Healthy Buildings Conference, Seoul. Available at: http://www.sustainablehealthybuildings.org/PDF/8th/martintaylor.pdf

[17] Morgan-Taylor, M. (2015). Regulating light pollution in Europe: Legal challenges and ways forward. Urban Lighting, Light Pollution and Society, Routledge, New York, 159-176.

[18] NANR 284. (2010). An Investigation into Artificial Light Nuisance Complaints and Associated Guidance. Defra. London, England.

[19] Kim, J.T. (2016). Legislative Approach of Preventing Light Pollution in South Korea. LUCI AGM. 2016 Conference; Seoul, South Korea, August 2016.

[20] CIE 150. (2003) Guide on the Limitation of the Effects of Obtrusive Light from Outdoor Lighting Installations.

[21] BRE. Buildings Research Establishment Environmental Assessment Method (BREEAM), England. Available at: http://www.bre.co.uk/

[22] CEC-400-2008-001-CMF. (2008). Energy Efficiency Standards for Residential and Nonresidential Buildings. California Energy Commission (CEC).

[23] State lighting. Conservation \& Natural Resources. Regulation of Outdoor Lighting. Chapter 71A.

[24] Light Pollution Prevention Act 2013 (2013). Ministry of Environment, Seoul, Republic of Korea 2013.

[25] Statutory nuisance, S. (1990). Environmental Protection Act 1990. 79(1).

[26] National Planning Policy Framework. Department for Communities and Local Government. accessed March 2012. Available at: https://www.gov.uk/government/uploads/system/uploads/attachment_data/file/ 6077/2116950.pdf. 
[27] Light Pollution. (2013). When is Pollution Relevant to Planning? Defra (UK). accessed 1 April 2016. Available at: http://planningguidance.planningportal.gov.uk/blog/guidance/light-pollution/when-is-lightpollution-relevant-to-planning/

[28] GN01. (2011). Available at: http://www.theilp.org.uk/documents/light-pollution/

[29] Salford CC v McNally. (1976). A.C. 379. Lord Wilberforce. 389.

[30] Malton Board of Health v Malton Manure Co. (1879). 4 Ex D 302.

[31] Godfrey v Conwy BC. (2001). Env LR 38 at 23.

[32] Bonwick v Brighton \& Hove. (2000). County Court claim BN 906 721. England (unreported).

[33] Bacon v Gwynedd CC Tywyn. (2004). case no. AB 300050. Wales (unreported).

[34] Stone Haven and District Angling Association v Stonehaven Tennis Club. (1997).Stonehaven Sherriffs Court, Scotland (unreported).

[35] Guidance Note on the Reduction of Light Pollution. GN01:2011. Available at: http://www.theilp.org.uk/ documents/light-pollution/

[36] Light Pollution Prevention Act in Korea 2013, 2016. (2013, 2016). Ministry of Environment, Seoul, Korea. 